\title{
Prof. Dr. Paul U. Unschuld erhält als erster Ausländer den Special Shulan Medicine Award
}

Der Medizinhistoriker, Pharmakologe und Sinologe Dr. Dr. Paul Ulrich Unschuld, Direktor des Instituts für Theorie, Geschichte und Ethik Chinesischer Lebenswissenschaften an der Charité - Universitätsmedizin Berlin, hat den Special Shulan Medicine Award erhalten (- Abb. 1). Die Auszeichnung ist damit erstmals einem Wissenschaftler außerhalb der Volksrepublik China verliehen worden. Sie ist mit 1 Mio. Yuan/RMB verbunden, das entspricht knapp 130.000 Euro. Unschuld wird für seine Arbeiten zur chinesischen Medizin, insbesondere für seine erstmalige philologische Übersetzung der antiken chinesischen medizinischen Schriften in eine europäische Sprache, das Englische geehrt.

Der Shulan Medicine Award ist eine Auszeichnung, die von der Zhejiang University Education Foundation und vom Shusen-Lanjuan Academician Talent Fund ins Leben gerufen worden ist. Sie dient der Förderung medizinischer Talente in China. Die vergebende Einrichtung, die Shusen-Lanjuan-Stiftung, ist eine nichtstaatliche Organisation. Mit Hauptund Nebenpreisen gilt der Shulan Medicine Award als der am höchsten dotierte Medizinpreis in der Volksrepublik China.

Unschuld ist ein ausgewiesener Experte auf dem Gebiet der chinesischen Medizin- und Wissenschaftsgeschichte. Er leitet seit mehr als zwölf Jahren das Institut für Theorie, Geschichte und Ethik Chinesischer Lebenswissenschaften an der Charité, eine interdisziplinäre Einrichtung für Forschung und Lehre, die mit dem Ziel

Dieser Beitrag basiert auf einer Pressemeldung der Charité - Universitätsmedizin Berlin: https:// www.charite.de/forschung/forschung aktuell/pressemitteilung/artikel/detail/hohe_chinesische_ehrung_fuer_lebenswerk/.

Deutsche Zeitschrift für Akupunktur 2020 • 63 (2): 111

https://doi.org/10.1007/s42212-020-00268-2

Online publiziert: 8 . April 2020

C Springer Medizin Verlag GmbH, ein Teil von

Springer Nature 2020

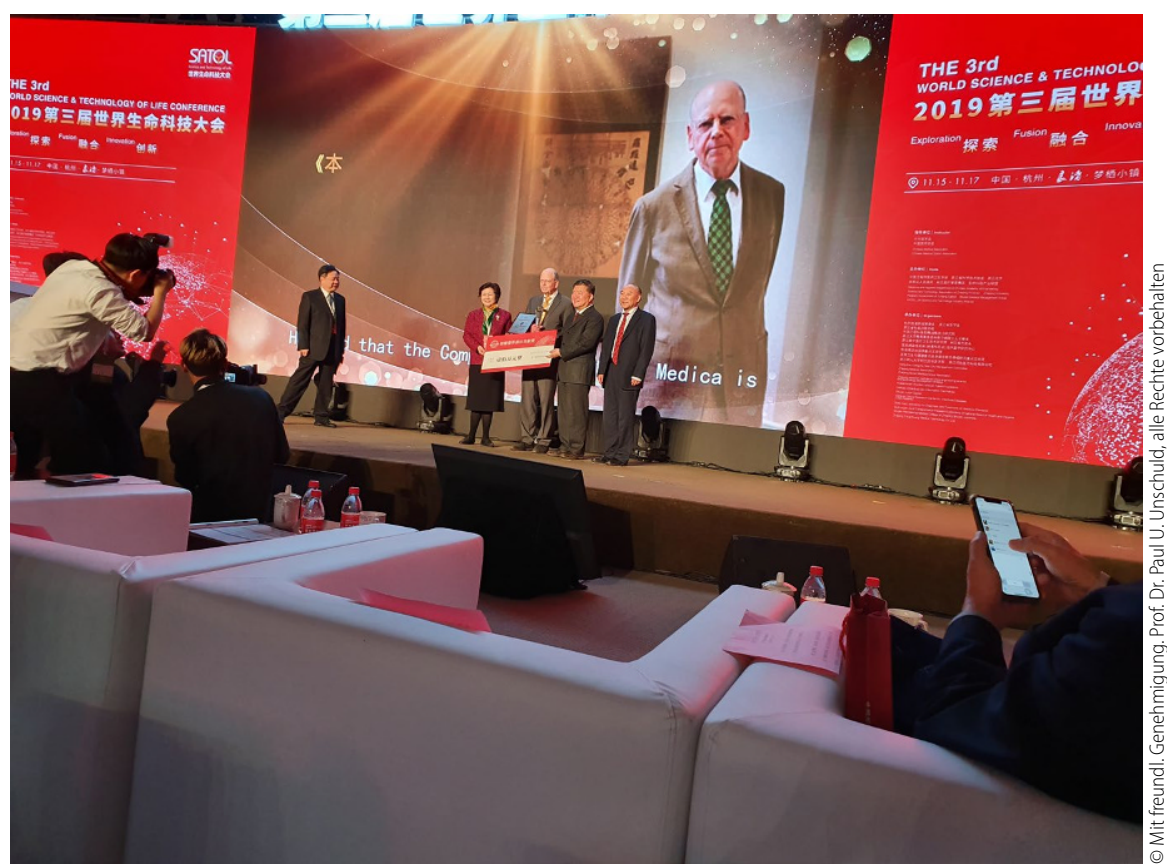

Abb. 1 Prof. Dr. Paul U. Unschuld erhält als erster Ausländer den Special Shulan Medicine Award

gegründet worden ist, für die zunehmende Verflechtung der westlichen und der ostasiatischen Lebenswissenschaften eine wissenschaftliche Plattform zu bieten. Es vereint grundständige Kompetenzen zu Medizin, Gesundheitswesen, Public Health, Lebenswissenschaften, Kultur, Geschichte, Philosophie und Ethik in China und der westlichen Welt.

Charité - Universitätsmedizin Berlin 